\title{
Jenis - Jenis Burung yang Dijumpai pada Areal Reklamasi Rawa Jakabaring Kota Palembang
}

\author{
Dian Mutiara $^{1 *}$, Syaiful Eddy ${ }^{2}$, Syamsul Rizal ${ }^{3}$, Syahirul Alim ${ }^{4}$. \\ *e-mail : dihartaa@gmail.com \\ 1,2,3 Dosen Program Studi Biologi Fakultas Sains dan Teknologi Universitas PGRI Palembang. \\ ${ }^{4}$ Alumni Program Studi Biologi Fakultas Sains dan Teknologi Universitas PGRI Palembang
}

\begin{abstract}
Research has been carried out on the types of birds found in the swamp reclamation area of Palembang city. The purpose of the study was to observe and determine the species of birds found in the former swampy swampy area of Jakabaring Palembang. Sampling was carried out from August to September 2020 using a purposive sampling method by exploring modified locations according to Pranotoet al., (2015) and MacKinnon et al., (2010). The collection was carried out by walking along the research area and determining the places frequented by birds. Birds encountered were identified based on morphological and sound characteristics. The results of the study found 7 orders, 15 families and 26 species. Of the 26 species of birds found, there were 19 bush birds and 7 species of swamp birds.
\end{abstract}

Keywords: birds, reclamation, swamp, species, Jakabaring.

\begin{abstract}
ABSTRAK
Telah dilakukan penelitian mengenai Jenis burung yang dijumpai pada areal reklamasi rawakota Palembang. Tujuan penelitian mengamati dan menentukan jenis burung yang dijumpai pada areal bekas hutan primer berawa Jakabaring Palembang. Pengambilan sample dilakukan Agustus sampai September 2020 menggunakan metode purposive sampling dengan menjelajah lokasi dimodifikasi menurut Pranoto et al (2015) dan MacKinnon et al., (2010). Pengambilan dilakukan dengan berjalan sepanjang areal penelitian dan menentukan tempat yang sering dikunjungi burung. Burung yang dijumpai diidentifikasi berdasarkan karakteristik morfologi dan suara. Hasil penelitian dijumpai 7 ordo, 15 familia dan 26 spesies. Dari 26 spesies burung yang dijumpai terdapat 19 burung semakbelukar dan 7 spesies burung rawa.
\end{abstract}

Kata Kunci : burung, reklamasi, rawa, jenis, Jakabaring.

\section{PENDAHULUAN}

Pengembangan kota Palembang mendorong pemerintah untuk melakukan perluasan wilayah, baik sebagai daerah perkantoran, perumahan, olahraga, wisata dan jalan lintas. Jakabaring merupakan daerah kawasan seberang Ulu yang dominan memiliki topografi berawa. Sebagai habitat rawa Jakabaring memiliki ekologi unik dan spesifik. Beralihnya fungsi lahan hutan rawa menjadi daerah perkotaan dan hunian cenderung 
berpengaruh pada mahluk hidup penghuninya diantaranya burung.

Alih fungsi lahan dari hutan skunder dan rawa menjadi habitat buatan mempengaruhi mahluk hidup penghuninya diantaranya kerabat burung. Burung merupakan kelompok hewan sensitif dan sangat terpengaruh keberadaannya akibat perubahan habitat. Menurut Ayat (2011), hilangnya pohon hutan dan semak belukar menyebabkan hilangnya tempat bersarang, berlindung dan mencari makan berbagai jenis burung. Tortosa (2007), Keanekaragaman tipe habitat akan mempengaruhi keanekaragaman jenis burung. Pengaruh penting lain adalah struktur vegetasi dan ketersediaan pakan pada habitat merupakan faktor utama yang mempengaruhi keanekaragaman jenis di suatu habitat.

Jakabaring sebagai areal reklamasi pengembangan perkotaan mengakibatkan berkurangnya luas hutan dan rawa. Penebangan hutan, penimbunan rawa dan pembakaran semak belukar juga mengakibatkan banyak habitat burung yang hilang. Dalam upaya meminimalisasi kehilangan hutan sekunder pemerintah telah melakukan penanaman beberapa jenis pohon di sepanjang jalan kawasan Jakabaring diantaranya Bungur (Langerstromiasp), Angsana (Pterocarpus indicus) dan Tanjung (Mimusopselengi). Diketahui kehadiran pohon ini bermanfaat sebagai pelindung, jalur hijau dan banyak dijumpai beberapa jenis burung. Alim et al,. (2020) pada salah satu Kawasan Jakabaring mencatat 14 spesies burung ordo Passiformes. Mutiara et al,. juga mencatat 31 spesies burung ordo Paseriformes yang diperjualbelikan di Pasar burung Palembang. Untuk menambah informasi jenis burung yang dijumpai pada Kawasan Jakabaring maka perlu dilakukan penelitian mengenai burung yang dijumpai pada areal ini.

\section{Metodelogi Penelitian}

Penelitian dilakukan di wilayah pemukiman Kawasan Reklamasi Jakabaring Sport City Palembang, Sumatera Selatan Agustus sampai September 2020 (Gambar 1). Wilayah yang diamati luasnya sekitar 43 ha dengan karakteristik wilayah cukup banyak memiliki tegakan pohon dan semak belukar serta adanya aliran sungai buatan. Wilayah ini awalnya merupakan rawa pasang surut yang kemudian direklamasi menjadi Kawasan Jakabaring Sport City pada tahun 2001.

\section{BAHAN DAN METODE}

$$
\text { Pengumpulan data pada }
$$
penelitian ini menggunakan metode survey langsung di lokasi penelitian dengan menjelajahi seluruh wilayah penelitian dan mengamati burung-burung yang ditemukan. Pengamatan terhadap objek burung dilakukan dengan melihat menggunakan teropong dan kamera serta mendengarkan suara kicauan burung, baik burung-burung yang ada di pohon maupun yang ada di semak belukar. Lokasi ditemukannya burung diberi tanda. Pengamatan dilakukan pukul 06.00 - 09.30 WIB dan pukul 15.30 17.00 WIB yang merupakan waktu aktivitas tertinggi Burung-burung Survey tidak dilakukan saat hujan dan berangin kencang. Identifikasi spesies burung menggunakan kunci determinasi menurut MacKinnon et al. (2010). 


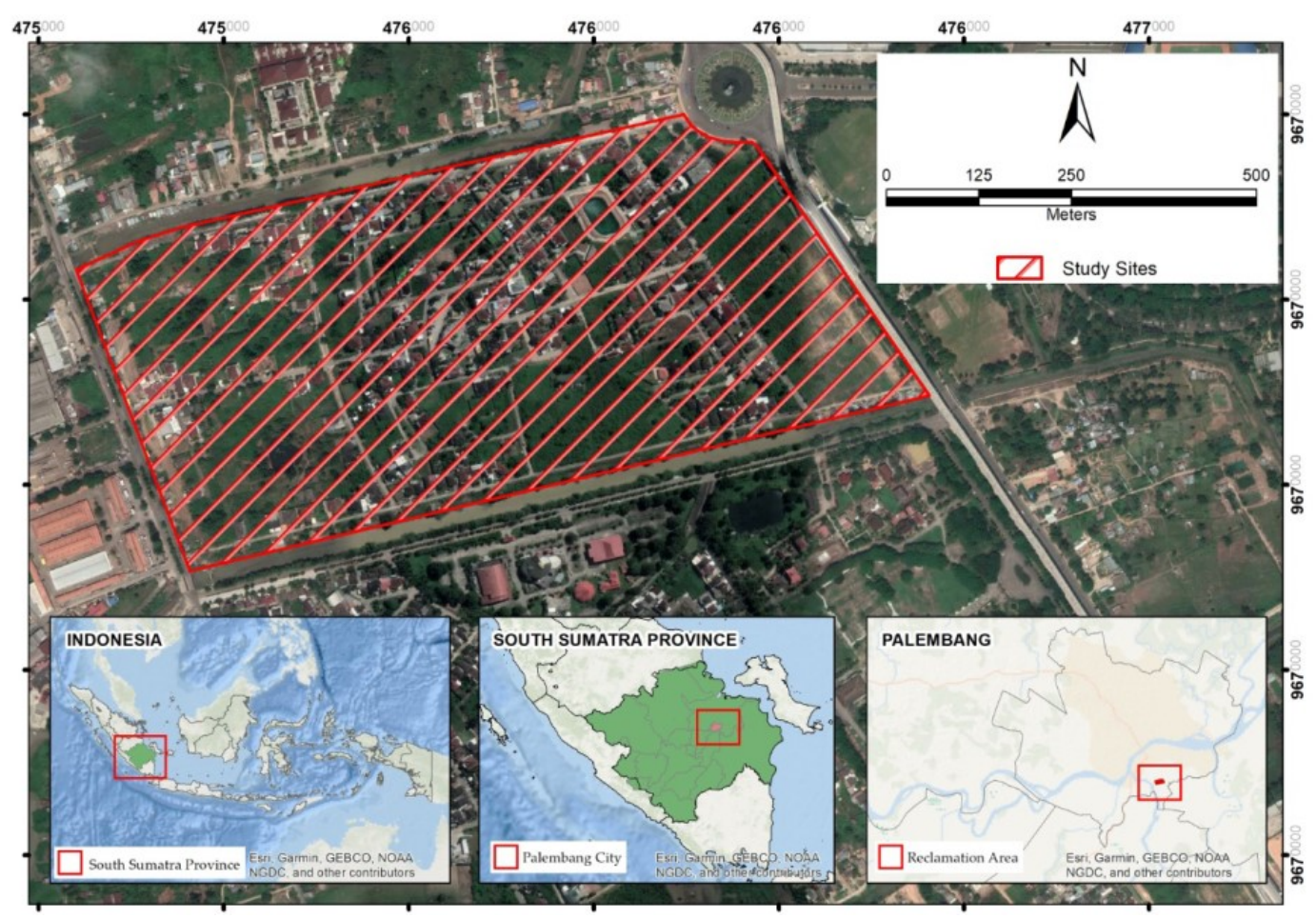

Gambar 1. Peta Lokasi Pengamatan

(Sumber :Googgle maps.2020)

\section{HASIL DAN PEMBAHASAN}

Pada tabel 1 dapat dilihat jenisjenis burung yang dijumpai di areal reklamasi Jakabaring Palembang Sumatera Selatan 7 ordo, 15 familia, 20 genus dan 26 spesies. Ordo yang dijumpai

Cuculiformes,

Passeriformes, Coraciiformes, Columbiformes, Gruiiformes, Piciformes, dan Ciconiiformes. Ordo Passeriformes dijumpai paling banyak spesies yaitu 16 spesies. Beranekaragam jenis burung yang dijumpai menandakan habitat hutan kota dan semak belukar dilokasi penelitian masih dapat mendukung kehidupan burung-burung. Beberapa jenis burung hidup pada habitat tertentu tetapi dapat juga menyesuaikan hidup pada tipe habitat yang mengalami perubahan, asalkan faktor lingkungan masih mendukung. Subasinghe dan Sumanapala (2014), mencatat 20 spesies burung pada hutan pinus dan habitat alam dan hutan modifikasi.
Jarulis et al , (2005) juga menjumpai 34 jenis burung, terdiri dari 27 genera, 18 familia dan 9 ordo pada pohon daerah perkotaan seperti mahoni (Swietenia mahagoni) dan pohon tanjung (Mimusopselengi). Iqbal et al., (2016a) menjumpai 36 spesies burung pada habitat hutan tanaman industry akasia yang masih dapat mendukung habitat keanekaragaman jenis burung. Iqbal et al., (2016b) juga mencatat 46 spesies burung pada habitat hutan kota Punti Kayu Palembang. Hal ini berarti beberapa jenis burung dapat beradaptasi dengan wilayah perkotaan asalkan diberi habitat yang cukup. Keanekaragaman burung pada areal reklamasi cukup tinggi walaupun pada lingkungan yang dimodifikasi. Menurut Hakim et al., (2020). Keanekaragaman jenis burung akan berbeda setiap habitat, habitat komplek akan memiliki keanekaragaman lebih tinggi 
Tabel 1. Jenis burung yang dijumpai pada areal reklamasi Jakabaring Palembang.

\begin{tabular}{|c|c|c|c|c|c|c|c|c|c|c|}
\hline \multirow[t]{2}{*}{ No } & \multirow[t]{2}{*}{ Ordo } & \multirow[t]{2}{*}{ Familia } & \multirow[t]{2}{*}{ Genus } & \multirow[t]{2}{*}{ Spesies } & \multirow[t]{2}{*}{ Nama lokal } & \multicolumn{4}{|c|}{ Status } & \multirow[t]{2}{*}{ Tempatdijumpai } \\
\hline & & & & & & $\mathbf{E}$ & D & TD & $\mathbf{T P}$ & \\
\hline 1 & Passeriformes & Ploceidae & Passer & Passer montanus & Gereja & & & $\mathrm{V}$ & & Cabang dan ranting \\
\hline 2 & & & Lonchura & Lonchura leucogastroides & Pipit & & & $\mathrm{V}$ & & Cabang dan ranting \\
\hline 3 & & Pycnonotidae & Pycnonotus & Pycnonotus aurigaster & Kutilang & & & $\mathrm{V}$ & & Cabang dan ranting \\
\hline 4 & & & & Pycnonotus plumosus & Berebah & & & $\mathrm{V}$ & & Cabang dan ranting \\
\hline 5 & & Hirundinidae & Delichon & Delichon dasypus & Layang-layang & & & $\mathrm{V}$ & & Cabang dan ranting \\
\hline 6 & & Silviidae & Orthotomus & Orthotomus ruficeps & Kecici & & & $\mathrm{V}$ & & Cabang dan ranting \\
\hline 7 & & & & Orthotomus atrogularis & Kecici talang & & & $\mathrm{V}$ & & Cabang dan ranting \\
\hline 8 & & & & Orthotomus sutorius & Kecici & & & $\mathrm{V}$ & & Cabang dan ranting \\
\hline 9 & & & Prinia & Prinia flaviventris & Kecici rawa & & & $\mathrm{V}$ & & $\begin{array}{l}\text { Cabang dan ranting } \\
\text { Semakbelukar }\end{array}$ \\
\hline 10 & & Zosteropidae & Zosterops & Zosterops pelpebrosus & Kacamata & & & $\mathrm{V}$ & & Cabang dan ranting \\
\hline 11 & & & & Zosterop satrifons & Kacamata & & & $\mathrm{V}$ & & Cabang dan ranting \\
\hline 12 & & Nectariniidae & Anthreptes & Anthreptes simplex & Madu polos & & & $\mathrm{V}$ & & Cabang dan ranting \\
\hline 13 & & & & Anthreptes malacensis & Madu kelapa & & & $\mathrm{V}$ & & Cabang dan ranting \\
\hline 14 & & & Nectariniidae & Nectarinia jungalaris & Madusringanti & & & $\mathrm{V}$ & & Cabang dan ranting \\
\hline 15 & & Dicaeidae & Dicaeum & Dicaeum $\mathrm{sp}$ & Cabai polos & & & $\mathrm{V}$ & & Cabang dan ranting \\
\hline 16 & & Chloropseidae & Aegithina & Aegithina viridissima & Cipoh jantung & & & $\mathrm{V}$ & & Cabang dan ranting \\
\hline 17 & Cuculiformes & Cuculidae & Centropus & Cenropus begalensis & Bubut & & & $\mathrm{V}$ & & Cabang dan semakbelukar \\
\hline 18 & Culumbiformes & Columbidae & Geopelia & Geopelia striata & Perkutut & & & $\mathrm{V}$ & & Cabang dan semakbelukar \\
\hline 19 & & & Streptopelia & Streptopelia chinensis & Terkukur & & & $\mathrm{V}$ & & Cabang dan semakbelukar \\
\hline 20 & Coraciiformes & Alcedinidae & Todirhamphus & Todirhamphus choris & Cekakaksungai & & & $\mathrm{V}$ & & Tepi sungai dan rawa \\
\hline 21 & & & Halcyon & Halcyon pileate & Cekakak cina & & & $\mathrm{V}$ & & Tepi sungai dan rawa \\
\hline 22 & & & & Halcyon smyrnensis & Cekakak belukar & & & $\mathrm{V}$ & & Tepi sungai dan rawa \\
\hline 23 & & Meropidae & Merops & Merop sleschenaulti & Kirik-kirik & & & $\mathrm{V}$ & & Tepi sungai dan rawa \\
\hline 24 & Gruiiformes & Ralliidae & Amaurornis & Amaurornis phoenicurus & Ayam-ayam & & & $\mathrm{V}$ & & Tepi sungai dan rawa \\
\hline 25 & Piciformes & Picidae & Dendropcopos & Dendropcopos sp & Pelatuk & & & $\mathrm{V}$ & & Pohon dan cabang \\
\hline 26 & Ciconiiformes & Ardeidae & Ixobrychus & Ixobrychus xinnamemomeus & Burung gelam & & & $\mathrm{V}$ & & Tepi sungai dan rawa \\
\hline
\end{tabular}

KET. E: Endemik, D:Dilindungi, TD:tidakDilindungi TP: Terancam punah ( v: Ya, - :tidak) Ayat (2011) dan (MacKinnon et al., 2010) 
Ordo Passeriformes familia Ploceidae, dijumpai 1 spesies Passermontanus dan Lonchura leucogastroides. P. montanus dijumpai berkelompok memakan lumut dan serangga yang terdapat pada sela kulit pohon. Menurut (Hakim et al 2020, Pandey,et al, 2021) P. montanus merupakan jenis paling umum dijumpai pada beragam habitat. L. leucogastroides dijumpai bertengger pada bungur setelah beraktivitas mencari makan pada tanaman padi dan rumput pada persawahan. Kedua spesies ini memanfaatkan pohon sebagai tempat tinggal karena ditemukan sarang yang dihuni kedua spesies tersebut. Alim et al., (2020). Juga menjumpai kerabat ordo Passeriformes pada pepohonan hutan kota kawasan Jakabaraing Palembang.

Ordo Passeriformes (Pycnonotidae) dijumpai 2 spesies Pycnonotus aurigaster dan Pycnonotus plumosus. Spesies ini dijumpai bertengger dan terlihat mencari makan pada pohon. Burung - burung ini menjadikan pohon sebagai tempat berlindung dan mencari pasangan.

Familia Hirundinidae dijumpai 1 spesies yaitu Delicuchon dasypus beterbangan kemungkinan menangkap serangga di udara. Burung diamati jarang bertengger, kalaupun bertengger dijumpai pada ranting bungur mati bahkan sering dijumpai bertengger di kabel listrik di lokasi.

Familia Silviidae dijumpai 4 spesies yaitu Orthotomus ruficeps, Orthotomus atrogularis, Orthotomus sutorius dan Prinia flaviventris. Kerabat burung ini sering dijumpai pada pepohonan dan semak terbuka, aktif dan mengeluarkan suara yang khas. Burung-burung juga dijumpai pada pohon tetapi tidak lama. Diduga hanya singgah bertengger setelah melakukan aktivitas pada kawasan ladang dan semak belukar yang terdapat disekitar lokasi.
Family Zosteropidae dijumpai 2 spesies Zosterops pelpebrosus, Zosterop satrifons. Walaupun status burung ini tidak dilindungi tetapi kedua spesies ini sudah jarang dijumpai.

Spesies burung yang dijumpai pada pohon, semak dan kawasan terbuka merupakan jenis-jenis burung yang dapat beradaptasi dengan kawasan hunian yang berubah walaupun keberadaannya belum tentu sesuai dengan habitat yang diinginkan. Menurut Nugroho et al, (2013) beberapa spesies burung dapat beradaptasi dengan kehadiran manusia.

Familia Nectariniidae dijumpai tigas pesies yaitu Anthreptes simplex, Anthreptes malacensis, dan Nectarinia jungalaris. Familia Dicaidae dijumpai 1 spesies yaitu Dicaeumsp. Familia Chloropseidae dijumpai 1 spesies Aegithina viridissima.

Ordo Cuculiformes (Cuculidae) dijumpai 1 spesies yaitu Cenropus begalensis. Burung ini merupakan penghuni semak belukar disekitar lokasi. Keberadaannya pada pohon kemungkinan bertengger karena terusik dan setelah keadaan aman akan kembali kesemak belukar.

Ordo Columbiformes (Columbidae) dijumpai 2 spesies Geopelia striata dan Streptopelia chinensis. Burung dijumpai bertengger pada ranting dan cabang pohon dan tanah terbuka

Ordo Coraciiformes (Alcedinidae) dijumpai 4 spesies Todirhamphus choris, Halcyon pileat, Halcyon smyrnensis dan familia Meropidae Merops leschenaultia. Sewaktu dijumpai burung berada di pinggiran sungai di lokasi.

Ordo Gruiiformes (Ralliidae) 1 spesies Amaurornis phoenicurus. Ordo Piciformes (Picidae) dijumpai 1 spesies Dendropcopos sp. Merupakan burung soliter hutan sekunder, lahan terbuka.

Ordo Ciconiiformes (Ardeidae) dijumpai 1 spesies Ixobrychus xinnamemomeus spesies ini merupakan 
burung rawa karena disekitar lokasi masih terdapat rawa dan sungai. Menurut Jarulis (2005), perbedaan jenis burung burung yang dihumpai juga dipengaruhi oleh habitat yang berdekatan.

Dalam pengamatan keberadaan burung pada areal penelitian keberadaan burung teramati dengan suara yang dihasilkan spesies. Pada dasarnya burung burung yang dijumpai memanfaatkan pohon dan semak belukar untuk melalui aktivitas biologi harian. Menurut Putra (2014) aktivitas harian burung diantaranya bertengger, pindah, terbang, bersuara, makan, istirahat, mengerami telur, menelisik bulu, dan membuat sarang

Burung yang dijumpai juga merupakan jenis burung yang biasa mendiami hutan dan beradaptasi dengan hutan skunder. Kehadiran jenis burung pada pohon yang ditanam pada areal reklamasi termasuk pohon tinggi yang dapat member perlindungan. Fungsi lain sebagai tempat mencari makan dan menemukan pasangan serta menandai daerah teritorial. Menurut Kurniawan et al., (2019) beberapa jenis aves banyak ditemukan dikawasan hutan dengan vegetasi pohon-pohon tinggi hal ini dikarenakan mereka lebih aman untuk berkembang biak dan bertahan hidup dari pada di dekat pemukiman atau kawasan wisata. Ditambahkannya juga perlu adanya tindak lanjut dari pemerintah setempat untuk upaya konservasi yang lebih serius dimasa yang akan datang agar dapat mencegah penurunan populasi yang signifikan. Rusmendo (2009) semakin kompleks habitat cenderung semakin tinggi keanekaragaman jenis burung dan cenderung rendah dalam ekosistem yang terkendali secara fisik dan cenderung tinggi dalam ekosistem yang diatur secara biologi.

Melihat keragaman jenis burung yang dijumpai pada pepohonan pada lokasi maka disarankan penanaman jenis pohon pilihan untuk taman kota, penghijauan di masa dating untuk kota Palembang seperti bungur dan Angsana . Kukreti dan Dinesh (2014), diversifikasi spesies tumbuhan berkontribusi pada kekayaan spesies dan keanekaragaman burung.

Menurut Gifari (2016). Taman kota sebagai ruang berisi komponen alam dan pemandangan ditimbulkan oleh keragaman vegetasi juga komponen buatan. Taman kota disediakan sebagai fasilitas sosial dan rekreasi, sumber oksigen kota merupakan ruang terbuka hijau yang juga dimanfaatkan oleh burung.

Dari jenis burung yang dijumpai pada pohon dan habitat yang berdampingan ternyata keberadaan pohon merupakan daya tarik beberapa jenis burung untuk beraktivitas, singgah, beristirahat, mencari makan, perlindungan predator juga berkembangbiak. Untuk mempertahankan dan menambah populasi burung maka keberadaan pohon perlu ditambah. Soenjoto et al., (2018) mengamati spesies burung pada bekas tambang batubara, spesies burung yang diamati bertambah sesuai bertambahnya usia vegetasi. Menurut Nurdin 2020) kehadiran satwa burung merupakan salah satu indicator biologis kualitas lingkungan. Hal ini diharapkan dapat menjadi pertimbangan untuk pemilihan jenis vegetasi sebagai ruang terbuka hijau. Subasinghe, 2014, pentingnya perencanaan yang tepat dan pengelolaan alam dan habitat yang dimodifikasi manusia dalam suatu area untuk konservasi avifauna.

\section{KESIMPULAN}

disimpulkan :

Dijumpai 7 ordo, 15 familia dan 26 spesies burung pada areal reklamasi rawa Jakabaring Palembang. Semak belukar, vegetasi pohon tinggi dan rawa dapat 
dijadikan sebagai habitat dan persinggahan burung. Burung yang dijumpai berstatus tidak dilindungi tetapi keberadaannya semakin jarang.

\section{DAFTAR PUSTAKA}

Alim, S. Eddy, S dan Mutiara, D. 2020.Karakteristikdan Deskripsi Ordo Passeriformes di Jalan Seniman Amri Yahya Jakabaring Palembang Sumatera Selatan. Jurnal Indobiosains .2(2).

Aryanti, N. A. Prabowo, A.dan Ma'arif, S. 2018. Keragaman Jenis Burung Pada Beberapa Penggunaan Lahan di Sekitar Kawasan Gunung Argopuro, Probolinggo. Jurnal Biotropika 6(1).

Ayat, A. 2011. Burung-Burung Agroforest di Sumatera. Bogor: World Agroforestry Center.

Ghifari,B. Hadi, M dan Tarwotjo. U. 2016. Keanekaragaman Dan Kelimpahan Jenis Burung Pada Taman Kota Semarang Jawa Tengah. Jurnal Akademika Biologi, 5(4).

Hakim, L. Abdoelah, O. S. Parikesit. Withaningsih, S. 2020. Impact of Agricultural Crop Type And Hunting On Bird Communities of Two Villages In Bandung, West Java, Indonesia. B IOD I VER $S I$ TA S. 21(1).

Iqbal, M.Prasetyo. C. Y. dan Setiawan, D. 2016a.The birds of Palembang Punti Kayu Recreation Forest, South Sumatra, Indonesia. Biovalentia: Biological Research Journal 2 (1).

Iqbal, M. Yustian, I. Setiawan, D. Saputra, R. Firman., Prasetyo, C. Y., and Fadli,D. (2016b). A rapid Bird Survey To Conservation Area of Industrial Acacia Timber Plantation, South Sumatra Province; with comparison to three different methods. Biological Research Journal. 2 (2).

Jarulis. Salsabila.A. dan Bakar, A.2005. Fauna Burung Di Taman Kota Dan Jalur Hijau Kota Padang. Gradien 1(2) : $98-104$

Kukreti, M. dan Bhatt, D. 2014. Birds of Lansdowne Forest Division and Adjacent Suburban Landscapes, Garhwal Himalayas, Uttarakhand, India: Community structure and seasonal distribution. $B I O D I V E$ $R$ S IT A S 15 (1):80-88

Kurniawan. N. Arifiyanto. A. 2017. Onitologi : Sejarah Biologi dan Konservasi. Penerbit UB Press.

Kurniawan, I.S.Tapilouw, F. S.Hidayat.T. dan Setiawan, W., 2019. Keanekaragaman Aves di Kawasan CagarAlam Pananjung Pangandaran. Titian Ilmu: Jurnal Ilmiah Multi Sciences, 11(1).

MacKinnon, J., Phillips, K., dan Balen, B. V. 2010. Burung-burung di Sumatera, Jawa,Bali dan Kalimantan. Rahardjaningtrah $W$, Adikerana A, Martodihardjo $P$, Supardiyono EK, Balen BS, penerjemah; Sumadipura $S$, Kartikasari A, editor.Bogor (ID): Puslitbang Biologi-LIPI.

Mutiara, D. Rizal, S dan Royan, M. 2020. Jenis-JenisBurung yang DiperjualBelikan di Pasar Burung Palembang Sumatera Selatan :Sainmatika 17(1).

Nugroho, M. S., Ningsih. S. dan Ihsan, M. 2013. Keanekaragaman Jenis Burung pada Areal Dongi-Dongi di Kawasan Taman Nasional Lore Lindu. Warta Rimba, 1(1): 1-9

Nurdin., Nurlaila.A., Kosasih. D., dan Herlina, N. (2020). Asosiasi Vegetasi Terhadap Komunitas Burung di Kampus I Universitas Kuningan. Quagga:Pendidikan dan Biologi 12 (2).

Pandey, N., Khanal,L ., Chapagain, N., Singh, K. D., Bhattarai. B.P., 
Chalise, M. K.2021. Bird Community Structure As a Function of Habitat Heterogeneity: A case of Mardi Himal, Central Nepal. B IOD I VE R S I T A 22 (1) : 262-271

Pranoto. E.A., Susetiyorini, R. E., dan Prihanta.

W.2015 Identifikasiburung di pulau KAI Maluku Tenggara. Birds Identification in The Kai Islands of Southeast Maluku Prosiding Seminar Nasional Pendidikan Biologi 2015, yang diselenggarakan oleh Prodi Pendidikan Biologi FKIP Universitas Muhammadiyah Malang, tema: "Peran Biologi dan Pendidikan

BiologidalamMenyiapkanGenerasi Unggul dan Berdaya Saing Global", Malang, 21 Maret 2015.

Putra, G. W., Harianto, S. P., dan Nurcahyani, N. 2014. Daily Behavior Turtledove (Streptopelia chinensis) In The Field Tennis University of Lampung. Jurnal Sylva Lestari2(3) : 93-100.

Rusmendro, H. 2009. Perbandingan Keanekaragaman Burung Pada Pagi dan Sore Hari di EmpatTipe Habitat di Wilayah Pangandaran Jawa Barat. Jurnal VisVitalis. 2(1) : 8-16.

Rudini., Labiro, E., dan Ihsan, M. 2016. Keanekaragaman Jenis Burung Pada Kawasan Hutan LinduNg KPH Dampelas Tinombo di Desa Sibualong Kec. Balaesang Kab. Donggala. Warta Rimba 4 (2): 6975.

Soendjoto, M. A., Riefani, M. K., Triwibowo, D., Metasari, D. 2018. Birds Observed During the Monitoring Period of 2013-2017 In The Revegetation Area of Ex-Coal Mining Sites in South Kalimantan, Indonesia. BIODIVERSITAS 19 (1) : 323-329.
Subasinghe, K., dan Sumanapala. A.P.2014. Biological and Functional Diversity Of Bird Communities In Natural And Human Modified Habitats In Northern Flank of Knuckles Mountain Forest Range, Sri Lanka. Journal B IO D I V E R S IT A S 15 (2) : 200-205.

Tobolka, M. 2011. Roosting of Tree Sparrow (Passer montanus) and House Sparrow (Passer domesticus). in White Stork (Ciconia ciconia) Nests During Winter. Tubitak35 (6) : 879-882.

Tortosa. F.S.,dan Villafuerte, R. 2000. Habitat Selection by Flocking Wintering Common Cranes (Grusgrus) at Los Pedroches Valley, Spain. Etologia 8 21-24.

Yustian, I., Zulkifli, H., Setiawan, A., Setiawan, D., Iqbal, M., Aprlian, I., Indriati, W., Saputra, R.F.,Sumantri, H., Pratama, R., Prastyo, C. Y., Noberio, D., dan Pragustiandi. G. 2017. Panduan Surveicepatkeanekaragaman fauna Di Sumatera Selatan. FMIPA Universitas Sriwijaya. Palembang 